\title{
The level of health literacy of secondary school students in Slovenia
}

\author{
Monika Sadar ${ }^{1 *}$, Karmen Erjavec ${ }^{2}$ \\ 'Secondary School of Nursing and Chemistry, School Centre Novo Mesto, Novo Mesto, Slovenia, ${ }^{2}$ Department of Social Sciences, Faculty of \\ Health Science, University of Novo Mesto, Novo Mesto, Slovenia
}

\begin{abstract}
Introduction: Health literacy of secondary school students is particularly important as they are exposed to higher health risk. Therefore, the aim of the study is to determine the level of basic health literacy, critical and mental health literacy, and numeracy of Slovenian secondary school nursing students using a cross-sectional comparative method.

Methods: The questionnaire measuring the level of basic numerical, critical, and mental health literacy was completed by 249 secondary school students, divided into a group of secondary school students attending a nursing program and students of others similar secondary schools such as economic technician, chemical technician and preschool education.

Results: Secondary nursing students were found to have statistically significantly higher levels of basic and mental health literacy than their peers, rather than numerical and critical health literacy. In addition, the results show that there is no statistically significant difference in the level of health literacy between the groups of secondary school students in relation to the environment (rural/urban area).

Conclusion: Numerical and critical health literacy should be systematically developed in nursing schools, and at least the basic aspects of health literacy should be introduced in all secondary school curricula.
\end{abstract}

Keywords: Health literacy; adolescents; rural environment; nursing

\section{INTRODUCTION}

The goal of health education in a modern health-conscious society is an empowered individual who is best able to care for his or her own health and the health of the community (1). To achieve this, an individual requires certain knowledge and skills that lead to healthy choices. Such an individual is highly health literate. The World Health Organization (WHO) classifies health literacy as a critical determinant of health, encompassing holistic skills, and competencies for life, in the Shanghai Declaration on Health Promotion - Agenda 2030. The introduction of a school curriculum to raise the level of health literacy is one of the basic goals of the Shanghai Declaration, to be achieved by the signatories by 2030 (2), but according to the available data, the East European countries are not (yet) implementing the activity declarations.

Although a high level of health literacy does not directly influence an individual's health status, it does influence knowledge about diseases, healthy lifestyles, and effective

Corresponding author: Monika Sadar, Secondary School of Nursing and Chemistry, School Centre Novo Mesto, Novo Mesto, Slovenia.

E-mail: monika.sadar@gmail.com

Submitted: 02 March 2021/Accepted: 09 June 2021

DOI: https://doi.org/10.17532/jhsci.2021.1272 use of preventive health services (3). Some sociodemographic characteristics that predict health status cannot be changed, such as gender, age, place of birth, hearing/vision problems, learning difficulties, and inability to work due to disability (4), but we can change other variables through various interventions that influence health self-assessment, such as health literacy interventions. Therefore, health literacy becomes one of the most important life skills needed by modern society, and it reflects the ability to make good health decisions in the context of daily life (5).

Health literacy becomes a source of empowerment for individuals for quality decision-making in health care, disease prevention, and health promotion and is largely associated with general literacy and education $(1,6)$. It is increasing due to general literacy interventions. The lack of skills to solve health problems leaves individuals, especially those from vulnerable groups, such as people living in rural areas, without the opportunity to positively influence their own health (7). Therefore, it is important that health literacy interventions cover the entire population. Since most of the young people in Central and East Europe are educated in secondary school, one of the easiest options for health literacy method is to introduce a secondary school subject on health education or sets of health content in different subjects. 
Over the past two decades, health and health policy experts have emphasized the need for children, and especially young people, to be health literate, as they have a greater opportunity to take an active role and control in making decisions about their own health and that of their peers (7). Health literacy is "placing one's own health, family health, and community health in context with an understanding of health status and with the socioeconomic factors and cultural values that influence it" (5).

In addition to general health literacy, it may include several specific dimensions of literacy, such as numerical, critical, and mental health literacy. Numerical health literacy is defined as the knowledge and skills required to use numerical operations, either alone or embedded in texts (8). The importance of developing numerical literacy is evident in the United Kingdom, where numerical testing has been mandatory since 2008 for physicians and nurses wishing to enroll and practice in the profession (9).

The main purpose of critical health literacy is for an individual to be able to make an informed decision based on the evaluation and analysis of information, setting the context in health information. Critical health literacy is "higher level cognitive and social skills that enable critical thinking and informed decision-making. These cognitive skills enable the individual to contextualize health data and use it to make informed health decisions" (10).

Researchers have also recognized the importance of mental health literacy, which is defined as "a multifactorial concept related to personal knowledge and beliefs about mental health, which in turn leads to the recognition of mental disorders, prevention, and successful management of mental illness" (11). According to the WHO, depression and anxiety disorders were among the top five causes of illness among adolescents in Europe in 2018. About 30\% of 15 -year-old girls and $15 \%$ of boys felt that their mental well-being was poor several times a week (12).

Research with American and German adolescents has shown that school health programs and curricula have a positive effect on increasing health literacy $(13,14)$. A US study measured the effect of including new health content on understanding nutrition labeling, how the body works and develops, and making healthy choices in a secondary school curriculum on student knowledge and behavior. The effect was strong as students showed more self-efficacy in making healthy choices after the intervention (13). German research focused on strengthening critical health literacy and found that implementing the health literacy curriculum strengthened health literacy as students transferred the content of the curriculum to their own projects in terms of designing relevant research questions, literature searches, critical evaluation, and demonstration (14).

Adolescents' health literacy may also potentially be influenced by where they live. An Australian study found that rural adolescents have statistically significantly lower mental health literacy than urban adolescents (15).

Existing research in the field of health literacy among secondary school populations has been conducted mainly in the United States, but also in Europe, especially in the United Kingdom, the Netherlands, and German-speaking countries (6). However, there is a gap in the study of this topic in the Central European, East European, and South European countries, which have a different culture or tradition of education and health than the West European countries and the USA, as it is based on public health and education (6). Therefore, the question arises as to how poorly secondary nursing students compare to other secondary school students in similar programs and whether this differs depending on the environment in which secondary students grow up (urban and rural) and other sociodemographic variables. The aim of the research was to determine the level of basic, numerical, critical, and mental health literacy of secondary school nursing students and other comparable secondary school programs in which they do not have health education or more complex health content, and whether it differs by residence, gender, and absenteeism.

Since individual studies in the United States and West Europe $(4,13,16,17)$ have shown that implementation of the health education curriculum can statistically significantly increase basic, numerical, critical, and mental health literacy, the first hypothesis is as follows:

$\mathrm{H} 1$ : There are statistically significant differences in the levels of basic, numerical, critical, and mental health literacy among secondary nursing students and others comparable secondary schools.

Since an Australian study showed (15) that adolescents living in rural areas have statistically significant lower levels of health literacy, the second hypothesis is as follows:

$\mathrm{H} 2$ : There are statistically significant differences in the level of health literacy between secondary school students living in urban areas and those living in rural areas.

Since studies $(18,19)$ have found that the risk for lower health literacy is among male adolescents, the third hypothesis is as follows:

H3: There are statistically significant differences in the level of health literacy between male and female secondary school students.

Since it was found in a study (18) that adolescents with lower absenteeism rate have higher level of health literacy, the fourth hypothesis is as follows:

H4: There is a statistically significant difference in the level of health literacy between secondary school students who have been absent from class up to 10 days in the past 12 months and others.

Since studies $(20,21)$ have found that secondary school students with less educated parents or guardians have lower levels of health literacy than their peers, the fifth hypothesis is as follows:

$\mathrm{H} 5$ : There is a statistically significant difference in the level of health literacy between secondary school students with more educated parents or guardians and others. Although there are some studies on the health literacy of the adolescent population, there is no known study to date that has examined how choose of secondary school program affects the level of health literacy and determine the level of health literacy of Slovenian secondary school students. The aim of the research was to determine the level of basic, numerical, critical, and mental health literacy of secondary school students. 


\section{METHODS}

A cross-sectional comparative method was used based on comparing the health literacy of secondary nursing students and secondary school students of other similar programs, such as economic technician, chemistry technician, and preschool education. We used stratified random sampling by first dividing the population into three main groups - secondary school students by three Slovenian regions East, West, and Central Slovenia. To include approximately 300 secondary school students in the survey, we randomly selected four secondary schools from all three regions, including one nursing school.

A total of 279 secondary school students from Slovenia were included in the sample, 30 secondary school students were excluded from further analysis because they did not complete the questionnaire. Of the 249 participants, 189 (75.9\%) were female and $60(24.1 \%)$ were male; 121 (48.6\%) of the respondents were secondary school students from nursing programs and $128(51.4 \%)$ were secondary school students from other similar secondary school programs where students are pursuing the vocational matura: Economic technician $(n=56)$, chemical technician $(n=33)$, and preschool education $(n=39)$. All secondary school students who participated in the study attended the $3^{\text {rd }}$ and $4^{\text {th }}$ year programs and were between 17 and 19 years old.

The survey questionnaire included two sections: A demographic section and a health literacy test. Demographic variables (gender, direction and year of education, type of residence, parent/guardian education, and absenteeism in the past 12 months) were selected on the basis of the existing scientific literature, where the previous authors examined the impact of individual variables on the level of health literacy (22). The health literacy test was prepared in the form of 16 variables testing health knowledge, basic health literacy, and numerical, critical, and mental health literacy of adolescents, based on the curricula of health education subjects in Slovenian secondary schools, expanded with questionnaires from two surveys $(17,19)$ and four variables were derived from the questionnaire "The Newest Vital Sign" (23). The linguistic equivalence of the questionnaire was established through translation and back translation by two independent, bilingual, and professional translators. The translators were informed about the purpose of the instruments. Finally, the questionnaire was revised by a panel of experts consisting of a language teacher and two nursing lectures to determine whether the concepts expressed in Slovene and English conveyed the same meaning. Cronbach alpha values were around 0.8 indicating acceptable internal consistency.

The data were obtained in the form of an online survey. The secondary school students answered the questions voluntarily, before conducting the survey, we obtained the consent of the school management, adult students, in the case of minor students, the consent of the student and his/ her parents. At the University of Novo Mesto, Faculty of Health Science, we obtained approval for the ethical appropriateness of the research committee, which included ethics committee.

A basic descriptive statistical analysis and the MannWhitney U-test or $t$-test for independent samples, the appropriate test was selected according to the calculation of the Kolmogorov-Smirnov test which was used. Statistical analysis was performed using SPSS 22.0 statistical program.

\section{RESULTS}

\section{Health literacy of secondary school nursing students}

First, we examined whether secondary nursing students and others differed statistically significantly in the level of health literacy, which includes numerical, critical, and mental health literacy, as well as basic health knowledge and skills. Considering the Kolmogorov-Smirnov test $(\mathrm{Z}=2.475$; $p=0.001)$, the Mann-Whitney U-test showed that there was a statistically significant difference $(p=0.001)$ between the groups. The results show that secondary nursing students $(M=22.157)$ have a statistically significant higher level of health literacy than other secondary school students $(\mathrm{M}=19.469)$, as shown in Table 1.

A statistically significant difference between the groups was found in the identification of sexually transmitted diseases, namely, gonorrhea $(p=0.001)$, hepatitis $\mathrm{B}(p=0.001)$, genital warts $(p=0.001)$, and syphilis $(p=0.001)$. In all these cases, the secondary nursing students showed more knowledge. There were also statistically significant differences in recognizing symptoms of stress $(p=0.034)$, condoms as the most effective contraceptive method $(p=0.005)$, and recognizing the diseases that human papillomavirus vaccination protects against $(p=0.001)$. The difference was also statistically significant in recognizing the symptoms of the mental illness schizophrenia $(p=0.001)$ and anxiety $(p=0.001)$. These cases also showed higher health literacy among secondary nursing students.

It was also examined whether the groups of secondary students differed statistically significantly in the level of numerical literacy. Considering the Kolmogorov-Smirnov test $(Z=0.517 ; p=0.952)$, the $t$-test showed no statistically significant difference between the groups of secondary students $(F=-0.717 ; p=0.474)$. The secondary nursing students scored an average of 1.124 on the numerical literacy test, while the other secondary students scored slightly higher with an average of 1.234 (Table 1).

It was then examined whether there was a statistically significant difference in the level of critical health literacy between the groups of secondary students. Considering

TABLE 1. The comparison of the arithmetic means of the basic, numerical, critical, and mental health literacy

\begin{tabular}{lccc}
\hline Aspects of health literacy & $n$ & Mean value & SD \\
\hline Basic health literacy & & & \\
$\quad$ Secondary nursing students & 121 & 22.157 & 4.227 \\
$\quad$ Other secondary students & 128 & 19.469 & 4.891 \\
$\quad$ Numerical health literacy & & & \\
$\quad$ Secondary nursing students & 121 & 1.124 & 1.249 \\
$\quad$ Other secondary students & 128 & 1.234 & 1.180 \\
Critical health literacy & & & \\
$\quad$ Secondary nursing students & 121 & 0.926 & 0.968 \\
$\quad$ Other secondary students & 128 & 0.938 & 0.801 \\
Mental health literacy & & & \\
$\quad$ Secondary nursing students & 121 & 2.596 & 1.327 \\
Other secondary students & 128 & 1.906 & 1.360 \\
\hline
\end{tabular}


the Kolmogorov-Smirnov test $(Z=0.614 ; p=0.845)$, the independent samples $t$-test showed that there was no statistically significant difference between the groups $(p=0.916)$. Otherwise, secondary nursing students in the studied sample scored lower $(M=0.926)$ than students in the other secondary school programs $(\mathrm{M}=0.938)$. The mean scores obtained show that the differences between the two groups are minimal (Table 1).

It was also analyzed whether there was a statistically significant difference between the groups of secondary students in terms of the level of mental health literacy. Considering the Kolmogorov-Smirnov test $(Z=2.286$; $p=0.001)$, the Mann-Whitney U-test showed that there is a statistically significant difference between the groups of secondary students at the level of $p=0.001$. Secondary nursing students $(M=2.595)$ have higher level of mental health literacy than other secondary students $(\mathrm{M}=1.906)$ (Table 1$)$.

The difference between groups was statistically significant for two of the four questions that tested mental health literacy. The difference was statistically significant for the recognition of schizophrenia $(p=0.001)$ and anxiety $(p=0.001)$. In both cases, secondary nursing students answered more correctly, $51.2 \%$ of secondary nursing students in the first case, $27.3 \%$ in the second, $52.1 \%$ in the third, and $25.8 \%$ in the rest (Table 2).

\section{The basic health literacy of secondary students according to the rural/urban environment}

Whether there is a statistically significant difference in the level of health literacy between secondary students who grew up in the city and those who grew up in the countryside are examined below. Considering the KolmogorovSmirnov test $(Z=0.379 ; p=0.999)$, the independent samples $t$-test revealed that there is no statistically significant difference $(p=0.860)$. Otherwise, for the sample included in the survey, secondary students from rural areas scored lower $(M=20.720)$ than secondary students from urban areas $(\mathrm{M}=20.829)$ (Table 3).

\section{The basic health literacy of the secondary students by gender}

Gender differences between groups of secondary students were identified in the follow-up procedure. Considering the Kolmogorov-Smirnov test $(\mathrm{Z}=0.878 ; p=0.423)$, the $t$-test for the independent samples showed that there were no statistically significant differences by gender $(p=0.360)$ (Table 3). Otherwise, for the sample included in the survey, female secondary students scored higher $(M=20.931)$ than male secondary students $(M=20.283)$.

\section{The basic health literacy according to the number of days of absence from school}

Whether there are statistically significant differences in the level of the health literacy with respect to the number of days of absenteeism in the past 12 months which is answered below. Taking into account the Kolmogorov-Smirnov test $(Z=0.703 ; p=0.707)$, the $t$-test for independent samples showed that there were no statistically significant differences $(p=0.867)$ between secondary students who
TABLE 2. The comparison of correct answers in the mental health literacy

\begin{tabular}{lcccc}
\hline $\begin{array}{l}\text { Secondary } \\
\text { school } \\
\text { students }\end{array}$ & \multicolumn{5}{c}{ Correct answers in percentage (\%) } \\
\cline { 2 - 5 } & $\begin{array}{c}\text { Depression } \\
(\%)\end{array}$ & $\begin{array}{c}\text { Schizophrenia } \\
(\%)\end{array}$ & $\begin{array}{c}\text { Anxiety } \\
(\%)\end{array}$ & $\begin{array}{c}\text { Anorexia } \\
(\%)\end{array}$ \\
\hline $\begin{array}{l}\text { Secondary } \\
\text { nursing } \\
\text { students }\end{array}$ & 81.0 & 51.2 & 52.1 & 81.0 \\
$\begin{array}{l}\text { Other } \\
\text { secondary } \\
\text { students }\end{array}$ & 71.1 & 27.3 & 25.8 & 76.6 \\
\hline
\end{tabular}

TABLE 3. The average value on the health literacy test according to environment gender, days of absence from school, and the level of education of the parents/guardians

\begin{tabular}{lccc}
\hline Demographic variables & $n$ & Mean value & SD \\
\hline $\begin{array}{l}\text { Environment } \\
\quad \text { Rural }\end{array}$ & 143 & 20.720 & 4.534 \\
$\quad$ Urban & 105 & 20.829 & 5.102 \\
$\quad$ Gender & 189 & 20.931 & 4.489 \\
$\quad$ Female & 60 & 20.283 & 5.560 \\
$\quad$ Male & & & \\
$\quad \begin{array}{l}\text { Days of absence from school } \\
\quad<10 \text { days }\end{array}$ & 128 & 20.786 & 5.003 \\
$\quad 10$ or more days & 121 & 20.636 & 4.515 \\
$\quad \begin{array}{l}\text { The level of education of the mother/ } \\
\text { guardian }\end{array}$ & & & \\
$\quad$ Lower level of education & 186 & 20.511 & 4.613 \\
$\quad$ Higher level of education & 61 & 21.459 & 4.198 \\
$\quad \begin{array}{l}\text { The level of education of the father/ } \\
\text { guardian }\end{array}$ & & & \\
$\quad \begin{array}{l}\text { Lower level of education } \\
\text { Higher level of education }\end{array}$ & 211 & 20.701 & 4.793 \\
\hline & 35 & 21.086 & 4.810 \\
\hline
\end{tabular}

missed school 10 or more days in the past 12 months and also those absent for $<10$ days. Otherwise, for the sample included in the research, it is considered that the secondary students with a lower number of days of absence achieved a slightly higher $(M=20.786)$ number of points than the secondary students with more days of absence from class $(\mathrm{M}=20.636)$ (Table 3).

\section{The basic health literacy according to the level of the parents' education}

It was also examined whether there are statistically significant differences in the level of health literacy according to the level of parental education level. First, the role of mother's/guardian's educational level was examined. Considering the Kolmogorov-Smirnov test $(Z=1.207 ; p=0.108)$, the $t$-test for the independent samples showed that there are no statistically significant differences $(p=0.178)$ between secondary students whose mothers/guardians are less educated and those whose mothers/guardians are more educated. Otherwise, for the sample included in the study, the secondary students of more educated mothers/guardians scored higher $(\mathrm{M}=21.459)$ than the secondary students of less educated mothers/guardians $(\mathrm{M}=20.511)$ (Table 3).

Similarly, the role of education of fathers/guardians is examined. Considering the Kolmogorov-Smirnov test $(Z=0.606$; $p=0.856$ ), the $t$-test for the independent samples shows that there are no statistically significant differences $(p=0.661)$ 
between the secondary students whose fathers/guardians are less educated and those whose fathers/guardians are more educated. Otherwise, for the sample included in the survey, the secondary students of more educated fathers/guardians score higher $(\mathrm{M}=21.086)$ than the secondary students of less educated fathers/guardians $(\mathrm{M}=20.701)$ (Table 3$)$.

\section{DISCUSSION}

Health professionals and health policy-makers agree that adolescents need to be health literate because with more health knowledge, they are more likely to take an active role and control in making decisions about their own health and the health of their peers and others (7).

The results of the study show that place of residence does not play an important role in the level of health literacy. This is in contrast to an Australian study which found that adolescents living in rural areas have statistically significantly lower mental health literacy than adolescents living in urban areas (15). The reason for this may lie in the rural characteristics of both continents. While Australian rural adolescents tend to live hundreds of kilometers from urban areas, Europe tends to be more densely populated and less diverse in lifestyle.

The results of the study confirm the hypothesis that secondary school nursing students have a statistically significant higher level of basic health literacy than their peers. The difference between the groups is evident in knowledge of sexually transmitted diseases, effective methods of contraception, and knowledge of diseases that human papillomavirus vaccination protects against. The secondary school nursing students statistically typically recognize multiple sexually transmitted diseases. The difference is also evident in recognizing the most effective method of protection against sexually transmitted diseases. The reason for this is likely that they pay a lot of attention to sex education in school, while their peers are exposed to significantly less of this information. The data are important because it tells us that secondary students who are not educated for the medical profession have a lack of knowledge about sexually transmitted diseases and effective contraceptive methods. Considering that most girls and boys are sexually active in secondary school, knowledge and skills are crucial to protect themselves from sexually transmitted diseases (25). A 2016 study on the sexual activity and behavior of Polish and Lithuanian adolescents found that they lacked knowledge about sexuality and, therefore, suggested the introduction of a sex education curriculum that provides adolescents with information about sexuality, contraceptive methods, and sexual violence (26). Meanwhile, in Slovenia, it was found that those who do not use contraceptive methods also do not take note of the content of sex education in school (27). Therefore, the introduction of such a curriculum is useful.

The results also showed that secondary nursing students do not have higher levels of numerical health literacy than their peers. In the sample, peers were found to have a slightly higher average score on a numerical health literacy test than secondary school nursing students. On average, the level of numerical health literacy of secondary school nursing students and peers is quite low. The result suggests that this aspect of health literacy should also be addressed more in school, as it is important for health care work, for example, calculating the correct dose of medication, and for life in general, for example, reading nutritional values. The previous research has also shown that secondary school students have difficulty reading and interpreting food labels. However, in the same study, they found that secondary school students do not know the reasons for a healthy, most of them only know the reason to maintain a healthy weight with a healthy diet (13).

Similar to an Australian study, the results for our sample showed that secondary students had relatively poorly developed critical health literacy (28). The results do not support the hypothesis that there is a statistically significant difference in the expression of critical health literacy between secondary students who have a health education subject and those who do not. However, the secondary nursing students in our sample scored lower on the critical health literacy test than their peers. In an age where information is accessible at every turn, developing critical information literacy is critical. This is especially true today, during the COVID-19 epidemic, when reviewing health information, such as protective measures and vaccinations, in particular (29).

Research has also shown that secondary nursing students have a statistically significant higher level of mental health literacy than their peers. The level was tested with four questions that required secondary students to determine what the mental health problem was based on the symptoms they described. A similar study was conducted by Norwegian researchers in which they examined the effectiveness of a multiday intervention to increase mental health literacy. From the results, it can be concluded that Slovenian secondary students have higher mental health literacy than their Norwegian peers. However, it is not possible to generalize because the Norwegian study used an open-ended question type, whereas in our study, we chose a closed-ended question type where secondary students could choose from eight offered answers (17). However, the study did not examine an important aspect of mental health literacy, namely, secondary school students' stigma regarding mental illness. We suggest that future research also examines this aspect of health literacy.

The survey also shows no statistically significant differences in the level of health literacy by gender, similar to the 2020 survey for adolescents in Finland, the Czech Republic, Belgium, Austria, and Germany, while statistically significant differences between the sexes were shown in Poland, Estonia, and in North Macedonia (30). This can be partly explained by the result of the 2018 International Mathematical Literacy Survey PISA which also showed that there is no gender difference in mathematical literacy in Slovenia, while it showed a minimal difference in favor of boys in Poland and a higher difference in favor of girls in North Macedonia (31).

The study also does not confirm the hypothesis that there is a statistically significant difference in the level of health literacy between secondary students who have not visited a doctor in the past 12 months or have visited him $<10$ times and others. While in Germany (24), it was found that adolescents visiting a doctor at least twice in the past 12 months showed a statistically significant association with low level 
of health literacy. The reason why there were no statistically significant differences between groups in our study is that individuals who visited a doctor more than once have more interactions with health professionals and the health-care system. However, health-care professionals who are aware of the importance of appropriate communication with patients can help to increase the level of health literacy of patients through the right kind of communication (32).

Similar to the Canadian study, the study found no differences in health literacy and parental education (18). Regarding the relationship between parents' educational level and their children's health literacy, it was found in Egypt that there is a positive relationship between these two factors and that children of parents with higher educational level have more knowledge and communication skills on health issues, more acceptable behavior, and higher efficiency in solving their own problems than peers of parents with lower educational level (21). However, Chinese research has shown that students whose parents have higher education have the lowest level of health literacy (3). The level of health literacy is influenced by a variety of factors, including parents and their education. As Europeans on average have a fairly high level of education, there are no significant differences between groups with higher and lower educated parents, as there are negligible numbers of individuals with completed or incomplete primary education (33). Based on the results of the research, we propose to introduce a health education curriculum at the level of the secondary education, the purpose of which would be to raise general health literacy and to strengthen numerical, critical, and mental health literacy skills. This would reduce the differences in the health literacy of individuals attending different secondary school programs.

A major limitation of the study is the inclusion of adolescents, who, according to the program, participate in health education and are likely to be more interested in health-related issues than the rest of the population. More accurate information on the role or influence of health education on health literacy levels would be obtained by experimenting with the introduction of health education content in nonhealth-related secondary school programs.

\section{CONCLUSION}

The study shows that secondary students' level of health literacy is not related to place of residence, gender, frequency of absenteeism, and parents' education. The choice of program of study plays an important role in the development of health literacy. Secondary nursing students have statistically significant higher level of basic health literacy than their peers. The study revealed a gap in numerical and critical health literacy skills among future health professionals. Both aspects of health literacy should be systematically developed. At the same time, at least the basic aspects of health literacy should be introduced in all secondary school curricula.

\section{DECLARATION OF INTERESTS}

Authors declare no conflict of interest.

\section{REFERENCES}

1. Okan O, Lopes E, Bollweg TM, Bröder J, Messer M, Bruland D, et al. Generic health literacy measurement instruments for children and adolescents: A systematic review of the literature. BMC Public Health 2018;18(1):166

https://doi.org/10.1186/s12889-018-5054-0.

2. World Health Organization. Shanghai Declaration on Promoting Health in the 2030 Agenda for Sustainable Development. Geneva: World Health Organization; 2019. Available from: https:/www.who.int/healthpromotion/conferences/9gchp/shanghai-declaration.pdf?ua=1. [Last access on 2019 Feb 18].

https://doi.org/10.1093/heapro/daw103.

3. Rong H, Cheng X, Garcia JM, Zhang L, Lu L, Fang J, et al. Survey of health literacy level and related influencing factors in military college students in Chongqing, China: A cross sectional analysis. PLoS One 2017;12(5):e0177776. https://doi.org/10.1371/journal.pone.0177776.

4. Prins $\mathrm{E}$, Monnat $\mathrm{S}$, Clymer $\mathrm{C}$, Toso BW. How is health related to literacy, numeracy and technological problem-solving skills among U.S. Adults? Evidence from the program from the international assessment of adult competencies (PIAAC). J Res Pract Adult Lit Second Basic Educ 2015;4(3):22-42. Available from: https://www.eric.ed.gov l?id=ej1083453. [Last access on 2020 Nov 20] https://doi.org/10.1371/journal.pone.0130257.

5. Kickbusch I, Maag D. Health literacy. In: International Encyclopedia of Public Health. Vol. 3. San Diego: Academic Press.

6. Sørensen K, Pelikan JM, Rothlin F, Ganahl K, Slonska Z, Doyle G, et al. Health literacy in Europe: Comparative results of the European health literacy survey (HLS-EU). Eu J Public Health 2015;26(6):1053-8.

https://doi.org/10.1093/eurpub/ckv043.

7. Borzekowski D. Considering children and health literacy: A theoretical approach. Pediatrics 2009;124(3):282-8.

8. Speros C. Health literacy: Concept analysis. J Adv Nurs 2005;50(6):633-40.

9. Marks R, Hodgen J, Coben D, Bretscher N. Nursing students' experiences of learning numeracy for professional practice. Adults Learn Math 2015;11(1):43-58. Available from: https://www.files.eric.ed.gov/fulltext/ej1092001.pdf. [Last access on 2020 Dec 5]

10. Sykes S, Wills J. Critical health literacy for the marginalised: Empirical findings. In: Okan O, Bauer U, Levin-Zamir D, Pinheiro P, Sørensen K, editors. International Handbook of Health Literacy. Bristol: Policy Press, University of Bristol; 2019. p. 167-81.

11. Jorm AF, Korten AE, Jacomb PA, Christensen H, Rodgers B, Pollitt P. "Mental health literacy": A survey of the public's ability to recognise mental disorders and their beliefs about the effectiveness of treatment. Med J Aust 1997;166(4):182-6.

https://doi.org/10.5694/j.1326-5377.1997.tb140071.x.

12. World Health Organization. Adolescent Mental Health in the European Region. Geneva: World Health Organization, Regional office for Europe; 2021. Available from: https://www.euro.who.int/_data/assets/pdf_file/0005/383891/adolescent-mh-fs-eng. pdf. [Last access on 2021 Jan 29].

13. Diamond C, Saintonge S, August P, Azrack A. The development of Building Wellness, a youth health literacy program. J Health Commun 2011;16(3):103-18. https://doi.org/10.1080/10810730.2011.604385.

14. Steckelberg A, Hulfenhaus C, Kasper J, Mühlhauser I. Ebm@school-a curriculum of critical health literacy for secondary school students: Results of a pilot study. Int J Public Health 2009;54(3):158-65. https://doi.org/10.1007/s00038-008-7033-1.

15. Marshall JM, Dunstan DA. Mental health literacy of Australian rural adolescents: An analysis using vignettes and short films. Aust Psychol Soc 2011:48(2):119-27. Available from: https://www.researchers.mq.edu.au/en/publications/mental-health-literacy-of-australian-rural-adolescents-an-analysi. [Last access on 2020 Dec 5] https://doi.org/10.1111/j.1742-9544.2011.00048.x.

16. Begoray DL, Wharh-Higgins J, MacDonald M. Secondary school health curriculum and healt literacy: Canadian student voices. Glob Health Promot 2009;16(4):35-42. https://doi.org/10.1177/1757975909348101.

17. Skre I, Friborg O, Breivik C, Johnsen LI, Arnesen Y, Wang CE. A school intervention for mental health literacy in adolescents: Effects of a non-randomized cluster controlled trial. BMC Public Health 2013;13:873.

https://doi.org/10.1186/1471-2458-13-873.

18. Wu AD, Begoray DL, Macdonald M, Wharf Higgins J, Frankish J, Kwan B, et al. Developing and evaluating a relevant and feasible instrument for measuring health literacy of Canadian secondary school students. Health Promot Int 2010;25(4):444-52. https://doi.org/10.1093/heapro/daq032.

19. Ye X, Yao Z, Liu W, Fan Y, Xu Y, Chen S. Path analysis to identify factors influencing health skills and behaviors in adolescents: A cross-sectional survey. Plos One 2014;9(8):e104406.

https://doi.org/10.1371/journal.pone.0104406.

20. Bloom B, Jones LI, Freeman G. Summary health statistics for U.S. children: National health interview survey, 2012. National center for health statistics. Vital Health Stat 2013;10(258):1-81.

https://doi.org/10.1037/e609502007-001

21. Alseraty WH. Parents' socioeconomic status and health literacy domains among 
shokrof preparatory school students, shokrof village, algarbia governorate, Egypt. J Educ Pract 2015;6(11):1-9. Available from: https://www.semanticscholar.org/ paper/parents\%27-socioeconomic-status-and-health-literacy-\%2c-alseraty/44252da72691387209f21a1f29db51a2f80c9149. [Last access on 2021 Jan 14]

22. Weiss BD. The newest vital sign: Frequently asked questions. Health Lit Res Pract 2018;2(3):125-7.

23. Berens EM, Vogt D, Messer M, Hurrelmann K, Schaeffer D. Health literacy among different age group in Germany: Result of a cross-sectional survey. Biomed Central Public Health 2016;16(1151):1-8. Available from: https://www.bmcpublichealth. biomedcentral.com/articles/10.1186/s12889-016-3810-6. [Last access on 2021 Jan 8] https://doi.org/10.1186/s12889-016-3810-6.

24. Susky S, Cesnaitiene VJ, Ossowsky ZM. Is health education at university associated with students' health literacy? Evidence from cross-sectional study applying HLSEU-Q. Biomed Res Int 2017;2017:8516843.

https://doi.org/10.1155/2017/8516843

25. Grlica S, Ramšak Pajk J. Spolnost in Zdravstvena Vzgoja Pri Mladostniku. Jesenice: Visoka Šola Za Zdravstveno Nego; 2012

26. Droszdol-Cop A, Sidlo-Stawowy A, Bumbuliene Z, Nowak-Brzezińska A, Białka A, Czajkowska M, et al. Sexual Activity and Behavior Among Adolescents in Poland and Lithuania; 2016. Available from: https://www.researchgate.net/publication/313383661_sexual_activity_and_behavior_among_adolescents_in_poland and_lithuania. [Last access on 2020 Nov 7]

27. Žalar A, Leskovšek E, Čeh F, Cugmas M. Spolna vzgoja v okviru vzgoje za zdravje v slovenskih srednjih šolah. In: Inštitut za varovanje zdravja Republike Slovenije; 2013.

28. Cusack L, Desha LN, Mar CB, Hoffmann TC. A qualitative study exploring high schoo students' understanding of, and attitudes towards, health information and claims. Health Exp 2017;20(5):1163-71.

https://doi.org/10.1111/hex.12562

29. Abel T, McQueen D. Critical health literacy and the COVID-19 crisis. Health Promot Int 2020;35(6):1612-3.

https://doi.org/10.1093/heapro/daaa040.

30. Paakkari L, Torppa M, Mazur J, Boberova Z, Sudeck G, Kalman M, et al. A comparative study on adolescents' health literacy in Europe: Findings from the HBSC Study. Int J Environ Res Public Health 2020;17(10):3543.

https://doi.org/10.3390/ijerph17103543.

31. Šterman Ivančič K. Program mednarodne primerjave dosežkov učencev in učenk. PISA 2018. In: Nacionalno Poročilo s Primeri Nalog iz Branja. Ljubljana: Pedagoški Inštitut; 2019.

32. Sim D, Yaun SE, Yun JH. Health literacy and physician-patient communication: A review of the literature. Int J Commun Health 2019;10:1-14. Available from: http://communicationandhealth.ro/upload/number10/DON-SIM.pdf [Last access on 2021 Jan 12]

33. Izobrazba. Višji Delež Žensk Kot Moških z Visoko Izobrazbo. Statistični Urad Republike Slovenije; 2021. Available from: https://www.ec.europa.eu/eurostat/cache/ infographs/womenmen_2017/si_sl/bloc-2a.html. [Last access on 2021 Jan 02].

\section{RELATED ARTICLES PUBLISHED IN JHSCI}

1. Branković $S$, Šegalo M, Pašalić A, Mahmutović J, Jaganjac A, Čustović-Hadžimuratović A, Vreto E. Awareness and attitude of secondary school students about drug use. JHSCI. 2013;3(1):55-9. 